\title{
Increased bone resorption is associated with greater seasonal fluctuation or 'cycling' of 25-hydroxyvitamin D
}

\author{
A. L. Darling ${ }^{1}$, F. Gossiel ${ }^{2}$, F. Robertson ${ }^{1}$, T. Hill ${ }^{3}$, J. L. Berry ${ }^{4}$, S. Johnsen ${ }^{5}$, R. Eastell ${ }^{2}$ and \\ S. A. Lanham-New \\ ${ }^{1}$ Department of Nutritional Sciences, University of Surrey, Guildford GU2 7HX, UK, ${ }^{2}$ Department of Human \\ Metabolism, University of Sheffield, Sheffield, S10 2RX, UK, ${ }^{3}$ School of Agriculture, Food and Rural Development, \\ Newcastle University, NE1 7RU, UK, ${ }^{4}$ Specialist Assay Laboratory (Vitamin D) Manchester Royal Infirmary M13 \\ $9 W L$, UK and ${ }^{5}$ Surrey Clinical Research Centre, University of Surrey, Guildford, Surrey, GU2 7XH, UK
}

It is established that adequate vitamin D (25-hydroxyvitamin D $(25(\mathrm{OH}) \mathrm{D})$ status is required for healthy bone mineralisation ${ }^{1}$. It is unknown whether seasonal fluctuations in $25(\mathrm{OH}) \mathrm{D}$ also impact on bone health ${ }^{2}$. If large seasonal fluctuations in $25(\mathrm{OH}) \mathrm{D}$ were associated with increased bone resorption ('breakdown') this would suggest a detriment to bone health. This analysis assessed whether there is an association between seasonal variation in $25(\mathrm{OH}) \mathrm{D}$ and bone resorption. The participants were $\mathrm{n}=279 \mathrm{Caucasian}(\mathrm{C})$ and $\mathrm{n}=88$ South Asian (A) women who participated in the D-FINES (Diet, Food Intake, Nutrition and Exposure to the Sun in Southern England) study (2006-2007). The main outcomes were serum 25(OH)D and the bone resorption marker urinary N-telopeptide of collagen (uNTX; creatinine adjusted), sampled once per season for each participant. $\mathrm{N}=154$ women $(\mathrm{mean}( \pm \mathrm{SD})$ age $51 \cdot 5 \mathrm{y}(12 \cdot 7)$ had full data for all four seasons of the year for $25(\mathrm{OH}) \mathrm{D}$, uNTX and body mass index (BMI) and were entered into this analysis. The average $\log 25(\mathrm{OH}) \mathrm{D}$ concentration over the course of the year (mesor) and the change in $\log 25(\mathrm{OH}) \mathrm{D}$ concentration from the highest to the lowest point of the year (amplitude) were calculated. This was expressed as a ratio (amplitude/mesor) to represent seasonal change in $\log 25(\mathrm{OH}) \mathrm{D}$ status. Non-linear mixed modelling showed that this ratio was predictive of uNTX (estimate $=0 \cdot 21,95 \%$ CI $(0 \cdot 18,0 \cdot 24), p<0 \cdot 001)$ (see table). The corresponding value for the mesor alone was: estimate $=-0 \cdot 035,95 \% \mathrm{CI}(-0 \cdot 04,-0 \cdot 03)$, $\mathrm{p}<0.001$. Therefore, individuals with a higher seasonal change in $\log 25(\mathrm{OH}) \mathrm{D}$, adjusted for overall $\log 25(\mathrm{OH}) \mathrm{D}$ concentration, showed increased levels of uNTX. Notably the effect size for the amplitude/mesor ratio (13.4) was larger than that of the mesor $(9 \cdot 1)$ which showed a negative association with uNTX.

\begin{tabular}{|c|c|c|c|c|c|}
\hline Model for uNTX & Estimate & $\mathrm{SE}$ & $95 \% \mathrm{CI}$ & $\mathrm{P}$ value & Effect Size \\
\hline Pre $C$ vs Post $C^{a}$ & $-0 \cdot 124$ & 0.934 & $(-1 \cdot 95,1 \cdot 71)$ & $0 \cdot 894$ & $0 \cdot 13$ \\
\hline Post $A$ vs Post $C^{b}$ & $0 \cdot 316$ & 1.885 & $(-3 \cdot 38,4 \cdot 01)$ & $0 \cdot 867$ & $0 \cdot 17$ \\
\hline Pre A vs Post $\mathrm{C}^{\mathrm{c}}$ & $0 \cdot 303$ & $2 \cdot 363$ & $(4 \cdot 33,4 \cdot 94)$ & 0.898 & $0 \cdot 13$ \\
\hline Body Mass Index (BMI) kg/m² & 0.073 & $0 \cdot 043$ & $(0 \cdot 01,0 \cdot 16)$ & $0 \cdot 085$ & 1.72 \\
\hline $25(\mathrm{OH}) \mathrm{D}$ mesor $\neq(\mathrm{nmol} / \mathrm{L})$ & -0.035 & $0 \cdot 004$ & $(-0.04,-0.03)$ & $<0 \cdot 001$ & $9 \cdot 13$ \\
\hline $25(\mathrm{OH}) \mathrm{D}$ ratio $(($ amplitude/mesor $) \neq$ & $0 \cdot 213$ & $0 \cdot 015$ & $(0 \cdot 18,0 \cdot 24)$ & $<0.001$ & $13 \cdot 41$ \\
\hline$-2 \log$ likelihood & $465 \cdot 7$ & & & & \\
\hline
\end{tabular}

$\neq \log$ transformed; pre = premenopausal; $\mathrm{C}=$ Caucasian, $\mathrm{A}=$ Asian, post = postmenopausal; abc $=$ control dummy variables for comparisons between ethnic and menopausal status groups and reference group (Post Cauc).

These findings suggest a possible detriment to bone health via increased levels of bone resorption in individuals with a larger seasonal change in $25(\mathrm{OH}) \mathrm{D}$ concentration. Also, the amount of seasonal change in $25(\mathrm{OH}) \mathrm{D}$ might be as important as overall $25(\mathrm{OH}) \mathrm{D}$ concentration for bone health. Further research is now required to investigate whether bone mineral density or fracture risk is affected by seasonal change in $25(\mathrm{OH}) \mathrm{D}$.

The D-FINES study was funded by the UK Food standards Agency (Project N05064). Measurement of uNTX was funded by the National Osteoporosis Society. All views are those of the authors alone.

1. van Leeuwen JP, van Driel M, van den Bemd GJ et al. (2001) Crit Rev Eukaryot Gene Expr. 11, 199-226.

2. Darling AL, Hart KH, Gibbs MA et al. (2013) Osteoporos Int. 25, 933-41. 